\title{
Journal of Awareness-Based Systems Change
}

\section{Moving from Transactional to Relational}

\section{Oliver Koenig, Eva Pomeroy, Megan Seneque, and Otto Scharmer}

With this second issue, the Journal of Awareness Based Systems Change is completing its first volume. For a new journal, its reception has been remarkable, with over 15.000 abstract views and file downloads in the first seven months since its inception. In the editorial of the inaugural issue, entitled The Birth of a Journal (Koenig, Seneque, Pomeroy \& Scharmer, 2021), we laid out the journal's intention: to develop a platform that makes visible the growing body of transdisciplinary work supporting and advancing systems change through awarenessbased methodologies and approaches. Integral to this intention are two underlying assumptions. First, the knowing needed to inform effective, regenerative change extends beyond the rational-cognitive realm privileged in so many of our systems and structures. Thus, we aim to support the extension of epistemologies that inform action to embrace relational, aesthetic, embodied and intuitive knowing on both individual and collective levels. Second, we contend that systems change from an awareness-based perspective is only possible if we make visible and interrogate two interconnected cycles at play in social reality creation: the re-generative forces and capacities of Presencing as well as its destructive counterpart of Absencing (Scharmer, 2016, 2018). This means 
examining power-where it lies, how it shapes our systems and structures and how it is experienced, both inside us and between us.

More than half a year has passed since the release of the inaugural issue in March of 2021, and the world is still under the collective grip of the global Covid19 pandemic. Polarization, at least in countries of the global north, has reached new worrying heights and, in many instances, has deepened existing division lines (Druckman et al., 2020). The past weeks also marked the closing of the COP 26 UN Climate Change Conference in Glasgow. For researchers and climate activists alike, the results of COP26 marked a dangerous compromise, with the announced targets for 2030 leading the earth to a 2,4 Celsius temperature increase by the end of the century (Climate Change Tracker, 2021). Indicatively the single largest delegation that had attended the COP26 was not a sovereign nation-state but lobbyists from the fossil fuel industry (Corporate Europe Observatory, 2021). The threshold we are facing as humanity is more evident than ever and the need to act collectively, generatively and systemically increasingly urgent.

What can lead us out of the self-inflicted deadlock and polarization, and how can we find ways that will enable us to successfully meet the challenges of the Anthropocene in the 21st century? The era of the lone hero-leader is long past as the scale and universality of issues like the climate crisis require an entirely new way of operating in every sector and around the world. This editorial is entitled "Moving from transactional to relational" which we read as one of the central themes running through all of the contributions in this second issue in different permutations: sometimes positioned as figure and sometimes as ground and with a focus on different sectors. In one way or another, all of the articles provide a sharp and critical diagnosis of our current moment, its dominating forces and ways of exercising power (over). A common narrative thread is that for too long we have been confined and restrained by western and hegemonic notions of rationalism, reductionism, empiricism, mechanism, dualism, and causality (Lange, 2018), which have particularly become embedded in the field of education. The move from transactional to relational on a systemic level is one that requires a substantive reevaluation of the ontological and epistemological positions and foundations that make up the fabric of social institutions and systems. It also requires to look at the various (unintended) consequences hegemonic epistemologies have inflicted and still inflict on humankind, having led to and manifesting themselves as various disconnects.

These disconnects can also be seen as manifestations of what Scharmer calls the three divides of our times: the ecological, the social, and the spiritual (Scharmer, 2016). All of these disconnects function in reciprocal ways. The way they appear and manifest seriously limits and restrains our individual and collective ability to address the complex issues and crises we are and will be facing. What is needed is the epistemological and ontological shift that has been framed as the relational turn (e.g., Emirbayer, 1997). Drawing from this turn, Spretnak reminds us: 
"...all entities in the natural world, including us, are thoroughly relational beings of great complexity, who are both composed of and nested within contextual networks of dynamics and reciprocal relationships. We are made entirely of relationships, as is the whole of the natural world." (2011, p. 4).

Such a turn requires both an expansion of our conception of humanness-as Galtung claimed necessary back in lectures from 1958 (Galtung, 2009)—and new action actions that allow us to radically re-connect with the planet, with one another and with our own innate (highest) potential to evolve and expand human consciousness.

All of these moves and turns require us to hold significant complexity-the complexity of our own multi-faceted being and that of others, as well as the multitude of inter-experience. In this way, moving from transactional to relational is a counter to polarization. Because relationship is fundamentally about connection, this move is also a counter to disconnection.

Taking the example of an African Indigenous wisdom tradition, Ubuntu, Martin Kalungu-Banda (2021, para 4) writes:

"Each being, animate or inanimate, possesses a life-force. This lifeforce connects all beings in one existence. For an African (and for many wisdom traditions), the soil and the stone contain a lifeforce. They are alive. Just like the human, the animal and the plant. This is why we treat every being with awe."

Mirroring this observation, recognition of relational and embodied ways of knowing are being reanimated in Indigenous research methodologies. Chilisa (2012), in particular explores, a relational ontology, epistemology and axiology, and the implications for research practices. She develops a relational axiology that is "embedded in the ubuntu relational ontology principles of (1) I am we, I am because we are; (2) relations of people with the living and the nonliving; and (3) spirituality, love, harmony, and community building" (Chilisa, 2012, p. 117). The mere act of apprehending such a mutual co-existence for Lange (2018) is a deeply ethical matter, one which calls upon us and our shared "responsibility for the lively relationalities of becoming, of which we are a part" (Lange, 2018). As an editorial team which is, as yet, solely composed of non-Indigenous academics we too, must embody, as Poirier (2008, p. 74) writes, a "position as apprentice and recognize the authority of our Indigenous teachers in the domain".

The articles in this issue speak from or to an emergent and relational body of knowing, and they regard this knowing as the source of right action that serves the well-being of individuals, organizations, communities and the planet. In doing so they suggest ways forward. Be it in our ways of thinking or by providing concrete and potentially actionable ideas, they offer possible means to tap into and activate what lies available as dormant possibilities (potentialities of becoming) in people and in the systems, they shape together. 


\section{Contributions of This Issue}

Bracketing the contributions from this issue both the "Commentary from the field" as well as "In Dialogue" speak to issues of social and racial (in-)justice and to the historically created in-built mindsets and practices within our political and cultural institutions that sustain them.

In a personal account, Dayna Cunnigham's Commentary from the Field discussed what awareness-based systems change, and in particular Theory U, has to offer to social and racial justice work. She contends that with an open mind we can intentionally look at the racialized violence around us and the dehumanization that it has caused and still causes. But it is only through an open heart and a caring gaze that we can shift these structures of violence and turn to effective action that is more than just euphemistically 'creating space at the table'.

Adrian Roux, Bevan Powell, Charity Nzegwu, Ermal Kirby and Jill Marsh are In Dialogue together with Megan Seneque and Sue Miller about the intersection of theology and racial justice in Black ministry. Representing a group of people, both ordained and lay from the Methodist Church in Great Britain, having engaged in an awareness-based systems change process they talk about what shaping an inclusive community means to them. In mirroring the inward-outward move discussed above their dialogue illuminates two things: First, it uncovers personal motivations and key influences which have contributed to the dialogue partners' own sense of calling to this work which led them to personal and collective action. Second, it highlights pathways on how justice, dignity and solidarity can be brought to life throughout all dimensions of the Church.

Opening up the line of peer-reviewed Original Articles, Peter Westoby's theoretical contribution frames this issue's theme most vividly as the dawn of an eclipse of relationality which has led to an alienation from the manifestations of life, both around us as well as within ourselves. As alternative, he offers both an ontological and a phenomenological pathway. On the ontological dimension, he proposes a new way of being that is experienced through a living polarity between the ideas enfolded within Jung's theory of individuation and Buber's theorizing about dialogue which allows to re-experience an intimacy with both one's Self and the Other. He reasons that such an ontological turn also demands a new kind of phenomenological—both social and ecological—perceptivity, one that departs from and leads back to the living process.

Shedding light on the field of higher education, Vivianna Rodriguez Carreon and Penny Vozniak present a craft in experiential teaching and embodied learning in a postgraduate course for peacebuilders and change-makers. Yet, they also intend to show how awareness and arts based practices in conjunction with methodologies and readings from Indigenous and phenomenological wisdom traditions philosophies hold the potential to overcome fragmentation (of the self) and evolve the human potential for a richer and more nuanced granularity of modes of expression beyond what is (and can be) written. Written, in itself, in a 
non-linear fashion, the paper offers the reader an ontological invitation to experience the unconventional unfolding of the course and engage in and with different literacies.

In an analytical paper, Michael Schön and Rolf Arnold delineate how the systems of vocational and higher education, both in terms of their governance as well as their prevailing practices, have fallen short on their own programmatic aspiration to prepare students to meet the demands the future holds. (Awareness-based) systems change efforts in the field of education can only succeed, they argue, if we approach them with fresh thinking and through a deeper source of creativity. For the authors, both of these demands can be found in the figure of the "reflexible person" for whose personality formation educational systems should be held accountable. To that end students need not only be equipped with abilities to observe what is going on in the outside world but also with the skillset necessary to observe and reflect in ways that include the self as the central locus for self-transformation.

As the fourth and final Original Article, Kirsi Hakio, presents an applied perspective on imagining together alternative ways of living with the Earth. In further developing the concept of Vertical Alignment as one's ability to move between different levels of attention, she draws upon and connects theoretical literature from the field of care ethics with empirical observations made in a design-based case study. In the latter, she gives a detailed account of the research collaboration between herself and an entrepreneurial couple in the field of nature tourism. Together they set out to construct and explore a prototype of future culture based on care and awareness-based co-creation.

A new feature in this second issue is a Book Review. Wendy Allen \& Lori Ryan do not just introduce and review Patricia Wilson's book The Heart of Community Engagement: Practitioner Stories from Across the Globe but also show how it had been used as part of a collective learning journey by students in a graduate program in early childhood leadership in a course on communitybased action research.

Lastly, also this issue showcases an "In the Making" Contribution as well as a "Discussant Commentary" in response. Luea Ritter \& Nancy Zamierowski introduce and reflect on the use of systemic constellations and systems sensing as a participatory and inquiry-based action research approach to help organizations build collective capacity for navigating complexity. The article takes the reader inside the experience of systems sensing with an action research pilot study conducted with organizations working for social change. In his "Discussant Commentary" Raghav Rajagopalan consider the article's primary contribution to the literature on awareness-based systems change as offering a valuable testimony to collective sensing, not as an idiosyncratic or imaginal, but rather as key data for systems to understand themselves.

As we put this second issue out into the world, we do so holding our initial intention to make visible and accessible the knowledge base needed to face our current challenges through awareness-based transformation. We invite you to 
experience each contribution as a manifestation of that intention-as small pieces of the larger picture of societal regeneration of which we are all a part. As Dr. Noel Nannup, the respected Aboriginal Elder and Board member of this Journal, put it so succinctly in his GAIA Journey opening address: "All we need to do is to have a piece of the path to the future and that is ours; and we polish that and we hone that, and we place that in the pathway that we are building, and of course as we build that pathway it changes us as the builders of the path and it also shapes the destination we are going to." (Nannup, 2020, 0:33)

\section{References}

Chilisa, B. (2012). Indigenous research methodologies. Sage.

Climate Action Tracker (2021, November). Warming projections global update. Climate Analytics and New Climate Institute.

https://climateactiontracker.org/documents/997/CAT_2021-11-09_Briefing_GlobalUpdate_Glasgow2030CredibilityGap.pdf

Corporate Europe Observatory (2021, November 8): Hundreds of fossil fuel lobbyists flooding COP26 climate talks. More lobbyists for big polluters than any national delegation [Blog]. Corporate Europe Observatory.

https://corporateeurope.org/en/2021/11/hundreds-fossil-fuel-lobbyists-flooding-cop26climate-talks

Druckman, J. N., Klar, S., Krupnikov, Y., Levendusky, M., \& Ryan, J. B. (2021). How affective polarization shapes Americans' political beliefs: A study of response to the COVID-19 pandemic. Journal of Experimental Political Science, 8(3), 223-234. doi:10.1017/XPS.2020.28

Emirbayer, M. (1997). Manifesto for a relational sociology. American journal of sociology, 103(2), 281-317. https://doi.org/10.1086/231209

Galtung, J. (2009). Theories of conflict. Definitions, dimensions, negations, formations. Based on lectures at the Columbia University (1958), University of Oslo (1969-1971), University of Zurich (1972) \& University of Hawaii (1973). Transcend.

Kalungu-Banda, M. (2021, November 3). Ubuntu 2.0: Can Ubuntu Philosophy inspire Africa's Future? [Blog] Medium. https://medium.com/presencing-instituteblog/ubuntu-2-0-can-ubuntu-philosophy-inspire-africas-future-96fa984c1b80

Koenig, O., Seneque, M., Pomeroy, E., \& Scharmer, O. (2021). Journal of AwarenessBased Systems Change: The Birth of a Journal. Journal of Awareness-Based Systems Change, 1(1), 1-8. https://doi.org/10.47061/jabsc

Lange, E. A. (2018). Transforming transformative education through ontologies of relationality. Journal of transformative education, 16(4), 280-301. https://doi.org/10.1177/1541344618786452

Nannup, J. (2021, April 18). A Piece of the Path - Dr. Noel Nannup._[Video] YouTube. https://www.youtube.com/watch?v=fAfNbKcO2dU

Poirier, S. (2008). Reflections on Indigenous CosmopoliticsPoetics. Anthropologica, 50(1), 75-85. http://www.jstor.org/stable/25605390

Scharmer, O. (2018). The essentials of Theory U: Core principles and applications. Berrett-Koehler Publishers. 
Scharmer, C. O. (2016). Theory U: Learning from the future as it emerges. (2nd ed.) Berrett-Koehler Publishers.

Spretnak, C. (2011). Relational reality. Green Horizon Books. 
